\title{
Nicotine inhibits the in vitro production of interleukin 2 and tumour necrosis factor- $\alpha$ by human mononuclear cells
}

\author{
G.S. Madretsma ${ }^{\text {a.b, * }}$, G.J. Donze ${ }^{a}$, A.P.M. van Dijk ${ }^{\text {a.b }}$, C.J.A.M. Tak ${ }^{a}$, \\ J.H.P. Wilson ${ }^{\mathrm{b}}$, F.J. Zijlstra ${ }^{\mathrm{a}}$ \\ a Dept. of Pharmacology, Erasmus University, P.O. Box 1738, 3000 DR Rotterdam, The Netherlands \\ ${ }^{b}$ Dept. of Internal Medicine II, University Hospital Dijkzigt, Dr Molewaterplein 40, 3015 GD Rotterdam. The Netherlands \\ Received 2 October 1995; accepted 22 February 1996
}

\begin{abstract}
Smoking protects against ulcerative colitis (UC), and treatment with nicotine patches has a beneficial symptomatic effect in patients with UC. To find an explanation for this response to nicotine in UC, we assessed the effects of nicotine on cytokine production by mononuclear cells (MNC). MNC were isolated from peripheral blood from healthy volunteers. Non-adherent MNC were preincubated with varying concentrations of nicotine or prednisolone for $24 \mathrm{~h}$ followed by addition of phytohemagglutinin $(10 \mu \mathrm{g} / \mathrm{ml}$ ). The concentrations of interleukin 2 (IL-2) and tumour necrosis factor- $\alpha$ (TNF $\alpha$ ) in the supernatants were determined by ELISA. Nicotine as well as prednisolone caused a significant inhibition of IL-2 and TNF $\alpha$ production. The maximum inhibition caused by nicotine was about $50 \%$ of that caused by prednisolone and was reached at concentrations equivalent to nicotine levels measured in plasma of smokers. These results indicate that nicotine exerts its immunoregulatory role through modulation of the cytokine production by non-adherent mononuclear cells.
\end{abstract}

Keywords: Nicotine; Cytokines; Human mononuclear cells

\section{Introduction}

During the last decade it has become clear that cigarette smoking not only increases the risk of developing cancer (Phillips, 1994) or cardiovascular

\footnotetext{
Abbreviations: UC, Ulcerative colitis; MNC, Mononuclear cells; IBD, Inflammatory bowel disease; IL-2, Interleukin 2; TNF $\alpha$, Tumour necrosis factor alpha; DMEM, Dulbecco's modified Eagles medium; PHA, Phytohemagglutinin; PBS, Phosphate buffered saline; FACS. Fluorescence-activated cell sorting

- Corresponding author. Tel.: +31-10-4087534; fax: + 31-104366839.
}

disease (Lepantalo and Lassila, 1991), but surprisingly, also has beneficial effects on some chronic diseases such as Alzheimer disease (van Duijn et al., 1991) and ulcerative colitis (Harries et al., 1982; Logan et al., 1984). Although the mechanisms underlying these beneficial effects are unknown, there is evidence that smoking influences the cellular (Miller et al., 1982) as well as the humoral immune system (Fisher and König, 1994; Srivastava et al., 1991; Barton et al., 1990).

Cigarette smoke contains a range of compounds with pharmacological activity. Of these compounds nicotine is the most important and it therefore seems 
logical to assume it to be responsible for most of the immunoregulatory effects of cigarette smoke. Treatment of patients with active ulcerative colitis (UC), a form of inflammatory bowel disease, with nicotine patches proved to have a beneficial effect (Pullan et al., 1994). The application of transdermal nicotine significantly improved symptoms in these patients. Nicotine may therefore have anti-inflammatory properties which could be important in the treatment of UC.

Recent studies have indicated an important role for T-cells in inflammatory bowel disease (IBD), especially in the initial phase of the inflammation. Cytokines produced by these cells play a key role in the pathogenesis of IBD. Elevated levels of TNF $\alpha$ and IL-2 have been reported in serum and stool of patients suffering from IBD, for most other cytokines there have been conflicting reports or they have not been adequately investigated (Sartor, 1994).

In order to find an explanation for the beneficial effect of nicotine in ulcerative colitis we examined the effect of nicotine on the production of two important mediators of inflammation in inflammatory bowel disease, interleukin 2 (IL-2) and tumour necrosis factor- $\alpha(\mathrm{TNF} \alpha)$.

\section{Materials and methods}

Approval for this study was obtained from the Medical Ethical Committee of the University Hospital of Rotterdam.

\subsection{Isolation of mononuclear cells}

Mononuclear cells (MNC) were isolated from 60 $\mathrm{ml}$ heparinized venous blood immediately after blood sampling. The method used was a modification of the technique described by Boyum (Boyum, 1968). Briefly, the blood was diluted $1: 1$ with Phosphate Buffered Saline (PBS; Oxoid, UK) before fractioning it by a one-step Ficoll-Paque gradient (Pharmacia, Sweden) centrifugation at $1100 \times \mathrm{g}$ for $15 \mathrm{~min}$ at $20^{\circ} \mathrm{C}$. The interphase was washed in PBS and resuspended in Dulbecco's Modified Eagles Medium (DMEM) containing HEPES and foetal calf serum
(Gibco, UK), supplemented with penicillin and streptomycin (Flow Lab, UK).

Following isolation the MNC were incubated in culture medium for $90 \mathrm{~min}$ in a water saturated atmosphere of $37^{\circ} \mathrm{C}$ containing $5 \% \mathrm{CO}_{2}$. Non-adherent MNC were harvested by repeated rinsing of the culture flasks (Costar. USA) with DMEM. The viability of the cells, assessed by Trypan blue exclusion, was over $95 \%$.

\subsection{Characterization of non-adherent mononuclear cell fraction}

The leucocyte subpopulations present in the nonadherent MNC fraction were analyzed by FACS using the monoclonal antibodies Leu 4, Leull and Leu 19 (Becton Dickinson, Mountain View, CA) that recognize CD3, CD16 and CD19, respectively. CD14 and $\mathrm{CD} 20$ positive cells were characterized by My 4 and B4 (Coulter Cytometry, Florida).

\subsection{Stimulation experiments}

Non-adherent MNC were cultured $\left(2 \times 10^{6}\right.$ cells $/$ well) in 24 wells culture plates (Costar, Cambridge MA, USA) in the absence or presence of varying concentrations of nicotine-hydrogen-tartrate (BDH, Poole. UK) or prednisolone-di-sodium-phosphate (Genfarma, The Netherlands) for $24 \mathrm{~h}$, followed by addition of phytohemagglutinin (PHA: $10 \mu \mathrm{g} / \mathrm{ml}$; Sigma, Belgium). After incubation for another 24 hours supernatants were harvested and stored at $-80^{\circ} \mathrm{C}$ until IL-2 and TNF $\alpha$ concentrations were assessed by ELISA (IL-2: Medgenix, Belgium, sensitivity: $70 \mathrm{pg} / \mathrm{ml}$ and TNF $\alpha$ : CLB, The Netherlands. sensitivity: $3 \mathrm{pg} / \mathrm{ml}$ ). The concentration of IL-2 and TNF $\alpha$ produced in the presence of PHA and absence of nicotine and prednisolone was used as control and set at $100 \%$. All incubations were performed in duplicate.

\subsection{Statistics}

The IL-2 and TNF $\alpha$ production are expressed as mean \pm SEM $(n=5)$.

Statistical comparisons between control and 
drug-treated cell cultures were made by paired $t$-test. A $p<0.05$ was considered to be significant.

\section{Results}

The non-adherent MNC fraction consisted primarily of T-lymphocytes (Table 1). The PHA-stimulated $\mathrm{TNF} \alpha$ production ranged from 3580 to $5430 \mathrm{pg} / \mathrm{ml}$, with a mean $\pm S E M$ of $4585 \pm 360 \mathrm{pg} / \mathrm{ml}$ and a median of $4810 \mathrm{pg} / \mathrm{ml}$. For IL-2 we measured a range of $1000-2660 \mathrm{pg} / \mathrm{ml}$, with a mean of $1615 \pm$ $295 \mathrm{pg} / \mathrm{ml}$ and a median of $1590 \mathrm{pg} / \mathrm{ml}$.

The production of IL- 2 and TNF $\alpha$ by these cells was inhibited in a dose dependent manner when nicotine was added $24 \mathrm{~h}$ prior to PHA (Fig. 1). This inhibition was only partial. For IL-2 the maximum effect of nicotine was observed at $10^{-7} \mathrm{M}$ (Fig. 1a) and for TNF $\alpha$ at $10^{-8} \mathrm{M}$ (Fig. 1b). A further increase of the nicotine concentration did not enhance the effect. There was a considerable interindividual variation in response to nicotine but enhanced production of the cytokines after addition of nicotine was never observed.

Addition of nicotine and PHA simultaneously or addition of nicotine after PHA, in contrast, had no effect on $\mathrm{LL}-2$ and TNF $\alpha$ production. Nicotine did not influence the viability of the cells, even in the highest concentration used $\left(10^{-5} \mathrm{M}\right)$.

Treatment of the non-adherent MNC with the corticosteroid prednisolone, also caused a dose dependent inhibition of IL- 2 and TNF $\alpha$ production. As with nicotine, the addition of prednisolone had to proceed that of PHA in order to cause a significant inhibition of IL- 2 and TNF $\alpha$ production at the lower

Table 1

Non-adherent mononuclear cell fraction

\begin{tabular}{lc}
\hline Cluster differentiation & Percentage \\
\hline CD3 & $72.1 \pm 2.3$ \\
CD16/CD56 & $15.1 \pm 0.8$ \\
CD20 & $7.3 \pm 1.9$ \\
CD14 & $0.6 \pm 0.1$ \\
Not classified & $4.9 \pm 1.2$ \\
\hline
\end{tabular}

Percentage of different cell types comprising the non-adherent mononuclear cells

Cells were characterized by FACS using the monoclonal antibodies Leu 14. Leu 11, Leu19, B4 and My 4.
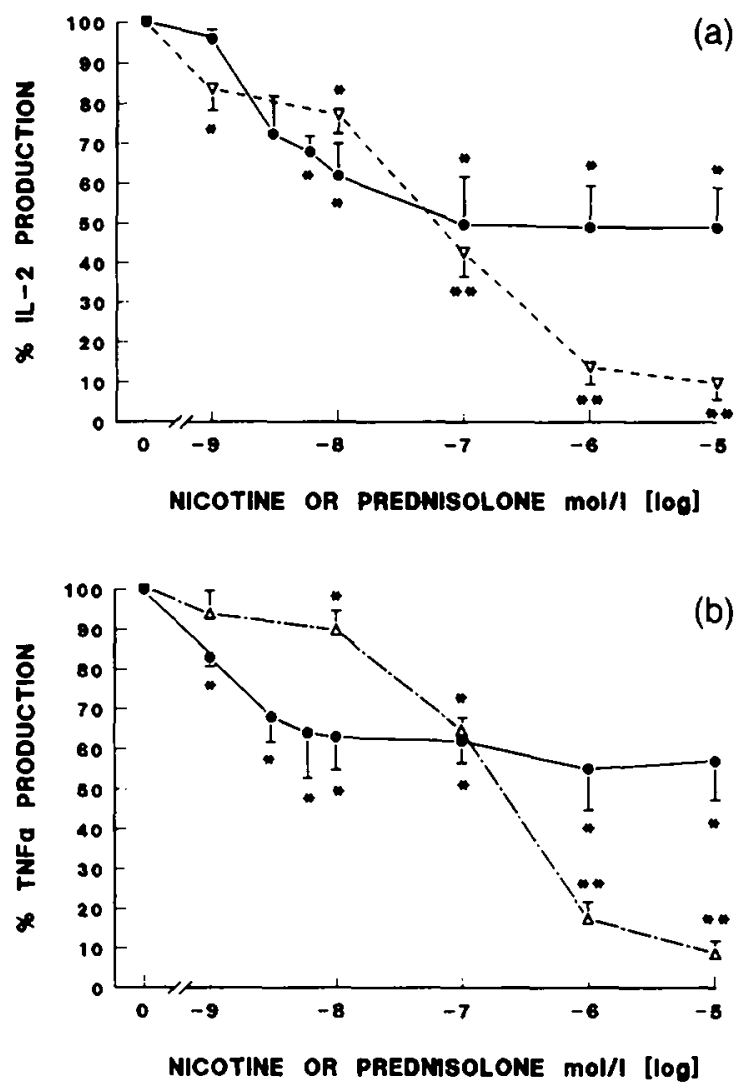

Fig. 1. Effects of nicotine (solid dot) and prednisolone (open triangle) on the synthesis of interleukin 2 (a) and tumour necrosis factor- $\alpha$ (b) in cultures of human peripheral blood lymphocytes stimulated with phytohemagglutinin (PHA: $10 \mu \mathrm{g} / \mathrm{ml}$ ). Cytokine production (percentage of control) is presented as mean \pm SEM (vertical bars) and represent 5 experiments performed on non adherent mononuclear cells obtained from 5 separate healthy volunteers. The paired $t$-test was used to compare control and drug-treated cell cultures. Prednisolone and nicotine caused a significant inhibition of cytokine production, ${ }^{\circ} p<0.05{ }^{\cdots} p<$ 0.01 compared with control cultures incubated with DMEM and PHA.

doses. In contrast to nicotine, the effect of prednisolone did not reach a plateau at the concentrations tested.

\section{Discussion}

The results of this study show that nicotine inhibits the in vitro production of IL-2 and TNF $\alpha$ by human non-adherent MNC. This is in agreement 
with our recent observation of an inhibition of cytokine production by mouse colonic mucosa after treatment with nicotine (van Dijk et al., 1995).

The inhibition of IL-2 and TNF $\alpha$ production by human MNC appears to be dependent on the concentration of nicotine, the duration of incubation and the individual donor. The potency of nicotine, however, was about $50 \%$ of that of prednisolone, a potent glucocorticosteroid. It is at present not clear whether nicotine administered transdermally is less effective clinically than prednisolone, as the clinical observation by Pullan et al. (1994) was on an additional anti-inflammatory effect of nicotine added to maintenance therapy with corticosteroids or 5-aminosalicylic acid, in the treatment of ulcerative colitis. In this study, nicotine reached its maximum effect at concentrations equivalent to those measured in plasma of smokers (Bowman and Rand, 1980).

We chose to use a cell population consisting predominantly of T-cells in this study for two reasons. Recent study has proven cyclosporin to be effective in the treatment of ulcerative colitis refractory to steroid therapy (Lichtiger et al., 1994). Cyclosporin exerts its immunosuppressive effect by suppressing the induction and amplification of T-cell responses by inhibiting cytokine gene activation, particularly IL-2 (Schreiber and Crabtree, 1992). Another finding indicating an important role for the $T$-cell in the pathogenesis of ulcerative colitis is the observation that appendectomy has a protective effect against ulcerative colitis. The appendix is a helper T-cell organ (Rutgeerts et al., 1994).

Inhibition of TNF $\alpha$ production by nicotine offers not only a possible explanation for the beneficial effect of this drug in UC but could also shed some light on the role smoking plays in the development of cancer. Smoking does not only elevate the risk of lung cancer but also of cancer in organs which do not come in contact with smoke itself (Heineman et al., 1994; Viscoli et al., 1993; Sood, 1991). A possible contributory factor to this carcinogenic effect of smoke 'at a distance' is that nicotine causes a more or less general suppression of the immune system. rendering the individual more susceptible for the development of neoplasms.

We conclude that nicotine has immunoregulatory effects through modulation of the cytokine production by non-adherent mononuclear cells.

\section{Acknowledgements}

We thank Miss M.R.M. Baert for her excellent technical assistance.

\section{References}

Barton, J.R., Raid. M.A., Gaze, M.N., Maran. A.G. and Ferguson, A., 1990. Mucosal immuno-deficiency in smokers and in patients with epithelial head and neck tumours. Gut 31: 37882.

Bowman, W.C. and Rand, M.J., 1980). Textbook of Pharmacology, Blackwell, Oxford, ch. 42.

Boyum. A., 1968. Isolation of mononuclear cells and granulocytes from human blood. Scand. J. Clin. Lab. Invest. 21 (suppl 97) $77-85$.

Fisher, A. and König, W., 1994. Modulation of in vitro immunoglobulin synthesis of human peripheral blood mononuclear cells by nicotine and cotinine. Clin. Invest. Med. 72: 225-232.

Harries, A.D., Baird, A. and Rhodes, J., 1982. Non-smoking a feature of ulcerative colitis. Br. Med. J. 284: 706.

Heineman E.F., Zahn, S.H., McLaughlin, J.K. and Vaught, J.B. 1994. Increased risk of colorectal cancer among smokers: results of a 26-year follow up of US veterans and a review. Int. J. Cancer 59: 728-738.

Lepantalo, M. and Lassila. R.. 1991. Smoking and occlusive peripheral arterial disease: Clinical review. Eur J. Surg. 157 83-7.

Lichtiger, S., Present, D.H., Kombluth, A., et al.. 1994. Cyclosporin in severe ulcerative colitis refractory to steroid therapy. New Engl. J. Med. 330: 1841-1845.

Logan. R.F.A., Edmond, M., Sommerville, K.W. and Langman, M.J., 1984. Smoking and ulcerative colitis. Br. Med. J. 288 : $751-753$.

Miller, L.G.. Goldstein, G., Murphy, M. and Ginns, L.C.. 1982 Reversible alterations in immunoregulatory $T$ cells in smoking. Chest 5: 527-529.

Phillips, A.J. 1994. The relationship of smoking and health: a review of the evidence. Can. J. Public Health 85: 77.

Pullan, R.D., Rhodes, J., Ganesh. S. and Mani, V., 1994. Trans dermal nicotine for ulcerative colitis. New Engl. J. Med. 330 $811-815$

Rutgeents, P., D'Haens, G.. Hiele, M., Gebos, K. and Vantrappen, G., 1994. Appendectomy protects against ulcerative colitis. Gastroenterology 106: 1251-1253

Sartor. R.B., 1994. Cytokines in intestinal inflammation: Pathophysiological and clinical considerations. Gastroenterology 106: $533-539$

Schreiber. S.L. and Crabtree, G.R.. 1992. The mechanism of action of cyclosporine $A$ and FK506. Immunol. Today 1.3 136-142.

Srivastava, E.D., Barton, J.R.. O'Mahoney. S., Phillips, D.J., et al., 1991. Smoking, humoral immunity and ulcerative colitis. Gut 32: 1016-1019.

S(x)d. A.K., 1991. Cigarette smoking and cervical cancer: meta- 
analysis and critical review of recent studies. Am. J. Prev. Med. 7: 208-13.

van Dijk, A.P.M., Madretsma, G.S., Keuskamp. Z.J. and Zijlstra F.J., Nicotine inhibits cytokine synthesis by mouse colonic mucosa. Eur. J. Pharmacol., in press van Duijn, C.M. and Hofman A., 1991. Relation between nicotine intake and Alzheimer's disease. Br. Med. J. 302: 1492-1494.

Viscoli, C.M., Lachs, M.S. and Horwitz, R.I., 1993. Bladder cancer and coffee drinking: a summary of case-control research. Lancet 341: 1432-1437. 